\title{
Basic recommendations for publishing in scientific journals of the psychiatry area
}

\author{
Héctor Esquivias-Zavala, ${ }^{1,2}$ Rodrigo Marín-Navarrete, ${ }^{3}$ Héctor Pérez-Rincón'
}

Departamento de Publicaciones, Dirección de Enseñanza, Instituto Nacional de Psiquiatría Ramón de la Fuente Muñiz, Ciudad de México, México.

2 Clínica de Obesidad y Control de Peso, Hospital General Dr. Manuel Gea González.

3 Unidad de Ensayos Clínicos en Adicciones y Salud Mental, Instituto Nacional de Psiquiatría Ramón de la Fuente Muñiz, Ciudad de México, México.

\section{Correspondence:}

Héctor Esquivias-Zavala

Departamento de Publicaciones,

Dirección de Enseñanza, Instituto

Nacional de Psiquiatría Ramón de la Fuente Muñiz.

Calz. México-Xochimilco 101, San Lorenzo Huipulco, Tlalpan, 14370,

Ciudad de México, México.

Phone: +52 (55) 41605130

Email: doctoresquivias@imp.edu.mx

\section{Citation:}

Esquivias-Zavala, H., Marín-Navarrete, R., Pérez-Rincón, H. Basic recommendations for publishing in scientific journals of the psychiatry area. (Recomendaciones básicas para publicar en revistas científicas del área de psiquiatría). Salud Mental, 41 (2), 53-56.

doi: $10.17711 /$ SM.0185-3325.2018.007

\section{Historical background}

Trends in the dissemination of scientific findings have changed over the years. According to the records, the publication of medical journals began during the second half of the 17th century, when various factors, such as the founding of new universities, the emergence of medical-scientific societies, the dissemination of discoveries in periodic publications, and the shift from Latin to vernacular languages, contributed to the progress of medicine and facilitated the dissemination of medical knowledge (Piqueras, 2007; Booth, 1990). The beginnings of a rudimentary, primitive globalization saw the spread of knowledge through private correspondence, books, brochures and pamphlets without systematization.

It was not until 1665 that pioneering medical societies began to publish their debates, giving rise to the first scientific publications: the French Journal des sçaves and the British Philosophical Transactions of the Royal Society (Argimon, Jiménez, Zurro, \& Vilardell, 2010). Their articles were initially disseminated without a standardized format or style. However, in an attempt to guarantee the validity of their publications, these two journals were the first to establish the systematic publication of research results.

By the beginning of the 19th century, the publication of original works in scientific journals in vogue (The New England Journal of Medicine [NEJM], The Lancet and the British Medical Journal [BMJ]) had become popular among researchers. During the second half of the 19th century, methodological description allowed the development of a comprehensive organization of manuscripts known as theory-experiment-discussion and, in the early 20th century, the medical community witnessed a gradual decline in publications with a literary style, coupled with an increase in standardized editorial criteria, which made it possible to establish a structured format to present scientific publications which followed the sections: Introduction, Method, Results and Discussion (IMRAD) (Liumbruno, Velati, Pasqualetti, \& Franchini, 2013; Sollaci, Enneking, \& Pereira, 2004; Sharp, 2002). The demand on the part of the scientific community for the reproducibility of experiments contributed to the rapid adoption of this format in the production of biomedical manuscripts. The IMRAD format guidelines are not an arbitrary provision of the publication, but rather a direct reflection leading readers to a better understanding of scientific discovery. They also facilitate the reading and location of specific information in each of the sections in articles.

The 20th century saw an enormous expansion of journals dedicated to medical specialties. After the end of World War II, in the 1950s the number of journals in the United States increased exponentially, which had an enormous influence not only on the development of world medical science, but also on its dissemination, and encouraged the adoption of English as the main language for international scientific publication (Argimon et al, 2010). Another factor that currently contributes to the dominance of English in scientific publication is the monopoly of British and American publishing houses, which edit over $76 \%$ of the journals in the area of psychiatry in the prestigious collection of the Journal Citation Report (JCR), to which Salud Mental belongs. In a review of the languages of publication in this area in its index, we find that over 90\% are published in English (Clarivate Analytics, 
2017). Going against this trend reduces the scope of publications, which invariably affects the bibliometric analysis of journals. This is, in other words, their Impact Factor (IF), obtained by dividing the number of articles published in a period of two years by the total number of citations they receive. Some researchers and editors question the suitability of this controversial indicator as a method for evaluating the importance or quality of scientific journals, which is an issue that warrants further analysis.

\section{Journals in the area of Psychiatry}

Like the historical development of the first medical journals, its publication by specialty areas represents an especially valuable contribution to knowledge. Publishing in psychiatry is complex, since psychiatry, psychology, addictions, and neuroscience journals converge in this area. There are approximately 3,200 indexed journals in the Social Science Citation Index (SSCI) of the JCR, 139 of which are in the area of psychiatry. The three best positioned journals in the 2016 edition of the JCR for this area were World Psychiatry (2018), with an outstanding IF of 26.56; JAMA Psychiatry (2018), with an IF of 15.30; and the American Journal of Psychiatry (2018), with an IF of 14.17 (Clarivate Analytics, 2017).

Salud Mental and the Revista Brasileira de Psiquiatria are the two only Latin American journals belonging to the JCR collection, which enjoys the greatest international prestige. This is not only due to the quality of the content of their publications, but also to historical, social, economic, and political factors. The main challenge currently facing Latin American publications is to become a competitive option, which requires a process of updating to bring them into line with trends and standards required by current scientific publication. For that purpose, a close relationship is required between authors and editors.

Among other functions, editors have the responsibility of updating and adapting publication rules in keeping with international trends and the best practices of the publication (International Committee of Medical Journal Editors [ICMJE], 2017; Babor et al, 2017). These updates vary, but can be roughly grouped into the following categories: a) Guidelines and editorial policies, concerning response times, standardized procedures for receiving manuscripts, editing, production, indexing, and the dissemination of published articles, b) Methodological aspects, involving the implementation of a peer evaluation system, the formation of a group of experts in various areas as part of the Editorial Committee, and, in particular, the adoption of international reporting standards corresponding to each type of methodology (Equator-Network, 2018).

The evolution of a journal always reflects the efforts of an editor (Pérez-Rincón, 2015); the demanding evaluation to which scientific journals are subject, together with the maintenance of the IF (the Holy Grail of current scientific publications), is perhaps a necessary evil for editors, but also for authors, who are evaluated more positively if their scientific production is published in journals with a high IF, meaning that the demand for high standards and quality publications are a challenge shared by editors and authors.

Given the current demands in this field, the aim of our editorial is to provide some basic recommendations for the publication of articles in scientific journals in the field of mental health.

Undertaking research requires a great deal of time, money, and effort. The process researchers "suffer" to be published and share their results with the scientific community occasionally becomes an odyssey. This is because when authors decide to publish their findings in prestigious journals, their manuscripts are subjected to a meticulous editorial review and intense methodological scrutiny. This process explains the high rejection rate documented in the main journals; JAMA Psychiatry (2018) reports an annual rejection rate of $85 \%$. Accordingly, authors must analyze their possibilities and propose a strategy in order to achieve their aim.

Thrower (2012) reports that between $30 \%$ to $50 \%$ of manuscripts are rejected before reaching the peer review stage and cites eight main reasons for rejection authors should avoid before submitting their manuscripts to a scientific journal:

1. The manuscript does not pass the technical screening since it contains total or partial plagiarism, the use of unauthorized images, incomplete or poor quality figures, incomplete or obsolete references, or the excessive use of socalled "gray literature" (books, public reports, non-scientific sources, etc.); 2. The manuscript is not part of the objectives or scope of the journal; 3 . The manuscript is incomplete, since it only presents certain descriptive observations and discusses its findings partially, ignoring previous findings; 4. The manuscript contains inaccurate statistical procedures and/or analyses; 5 . The conclusions cannot be justified on the basis of the background, objectives, and methods used; 6 . The manuscript is a small analysis of a larger study that contributes nothing new; 7 . The manuscript is difficult to understand due to the poor quality of the language; 8 . The manuscript is boring, fails to present anything new and is not of interest to readers and researchers according to the objectives and scope of the journal.

A first recommendation for researchers is to clearly delimit the scope of their results in order to select the right journal, even before beginning to write the manuscript, since its orientation, and even the style of writing, should match the scope and characteristics of the chosen journal. It is therefore essential to read the author's guidelines before submitting one's manuscript. In order to determine the ideal journal for publication, authors should ensure that the subject of the manuscript is of interest to that publication 
by reviewing the trends in the thematic content of the past three years.

The high rejection rate prior to peer review in some publications or, at best, before obtaining the relevant editorial modifications, is due to the fact that the authors failed to comply with or did not read the editorial guidelines, which results in a bothersome and unnecessary delay.

According to the publishing guidelines for biomedical journals established by the ICMJE (2017), the following aspects must be taken into account in the sections of the scientific report:

a) The title is particularly important: when it is novel and conveys the essence of the study, it can largely determine the success of the manuscript and, on the contrary, when the expectations of a novel, descriptive title are not met by the content, this can have a negative effect. The title should therefore be clear, brief, and concise and avoid the use of unusual terms. The evidence suggests that a title with these characteristics has a greater number of citations (Jacques \& Sebire, 2010; National Library of Medicine [NLM], 2017).

b) The abstract is one of the most important parts of the article. It should highlight the most novel and important aspects of the research, since it will help many readers to decide whether or not to continue reading the entire article. The abstract should therefore summarize four main aspects of the study: the purpose of the study, the main methods, the most important results, and the principal conclusions. Once the abstract has been written, the author must ensure that it does not exceed the required length.

c) Co-authorship must be reserved for those who have substantially contributed to the conception and design of the study, as in the collection, analysis and interpretation of the data and the critical review of the content until the approval of the final version. It is useful to include the institutions to which the co-authors are affiliated.

d) Keywords must be included after the abstract. These facilitate the search for the article in databases. Salud Mental recommends choosing these from the list in Medical Subject Headings (MeSh) (NLM, 2017) because the thesaurus is also used for indexing articles in PubMed, which increases the likelihood of the article being cited by other authors.

e) The acknowledgments section should include those who contributed to the study but did not meet the criteria for being co-authors, in other words, people who collaborated with technical or editorial support (ICMJE, 2017).

f) References must follow the citation and reference system requested in the author's guidelines. These are a guide to the type of scientific literature reviewed. They constitute a link between the research presented and previous research and provide a basis for the author's statements (ICMJE, 2017). It is therefore recommended to include recent original publications and classic articles in the area of study and to avoid the overuse of gray literature.

Some recommendations for ethical aspects in the relevant scientific publication to be considered include the following:

Specify funding and the role of study sponsors: The guidelines of the American Psychological Association (APA) regarding ethical conduct of research and conflicts of interest stipulate that not only should potential conflicts of interest be indicated, but also financial agreements or agreements with any product or service that has been used for the publication. In the event that no funding has been received, the authors must also declare this (APA, 2013).

Declare potential conflicts of interest: A conflict of interest exists when an author has a personal or financial relationship that could inappropriately influence their research work (Dickens \& Cook, 2006; ICMJE, 2017).

Grant a letter of authorization for the use of work: This is an indispensable requirement in the editorial policy of all publications. This document allows the publisher to: 1 . Distribute the work more widely, 2. Control its reuse by other people, and 3. Undertake the necessary procedures for the registration and administration of the copyright (APA, 2013).

The editorial review process is the first challenge authors face when submitting a manuscript for publication. Reading the authors' guidelines, established by each journal, provides valuable guidance to obtain a favorable response that will streamlines the editorial process. Before submitting your manuscript, making a last effort to ensure that it complies with the author' guidelines will have a favorable impact on the whole process.

\section{REFERENCES}

American Journal of Psychiatry. (2018, April 9). About the journal [Web log post]. Retrieved from https://ajp.psychiatryonline.org

American Psychological Association (APA). (2013). Publication Manual of the American Psychological Association, Sixth Edition. Washington, DC: American Psychological Association.

Argimon, J. M., Jiménez, J., Zurro, A. M., \& Vilardell, M. (2010). Publicación Científica Biomédica: cómo escribir y publicar un artículo de investigación. Barcelona: Elsevier.

Babor, T. F., Stenius, K., Pates, R., Miovský, M., O’Reilly, J., \& Candon, P.(2017). Publishing Addiction Science: A Guide for the Perplexed. London: Ubiquity Press. doi: 10.5334/bbd

Booth, C. C. (1990). The origin and growth of medical journals. Annals of Internal Medicine, 113(5), 398-402.

Clarivate Analytics. (2017, April 9). Journal Citation Report 2017 [Web log post]. Retrieved from https://clarivate.com/products/journal-citation-reports/

Dickens, B. M. \& Cook R. J. (2006). Conflict of interest: Legal and ethical aspects. International Journal of Gynecology \& Obstetrics, 92(2), 192-197.

Equator Network. (2018, April 9). Reporting guidelines for main study types [Web log spot]. Retrieved from http://www.equator-network.org

International Committee of Medical Journal Editors (ICMJE). (2018, April 9). Recommendations for the Conduct, Reporting, Editing, and Publication of Scholar- 
ly Work in Medical Journals. Retrieved from http://www.icmje.org/about-icmje/ faqs/icmje-recommendations/

Jacques, T. S., \& Sebire, N. J. (2010). The impact of article titles on citation hits: an analysis of general and specialist medical journals. JRSM Short Reports, 1(1). doi: 10.1258 /shorts.2009.100020

JAMA Psychiatry. (2018, April 9). About the journal [Web log spot]. Retrieved from https://jamanetwork.com/journals/jamapsychiatry

Liumbruno, G. M., Velati, C., Pasqualetti, P., \& Franchini, M. (2013). How to write a scientific manuscript for publication. Blood Transfus, 11(2), 217-226. doi: 10.2450/2012.0247-12

National Library of Medicine (NLM). (2017, April 9). Medical Subject Headings [Web log spot]. Retrieved from https://www.nlm.nih.gov/mesh/meshhome.html Piqueras, M. (2007). Aproximación histórica al mundo de la publicación científica. In: K. Mabrouki \& F. Bosch (Eds.), Redacción cientifica en biomedicina: lo que hay que saber (pp. 1-13). Barcelona: Fundación Dr. Antonio Esteve.
Pérez-Rincón, H. (2015). La evolución de una revista o los empeños de un editor. Paper presented at the XXX Reunión Anual de Investigación, Mexico City, s49-s50. doi: 10.17711/SM.0185-3325.2015.052.Supl1

Sharp, D. (2002). Kipling's guide to writing a scientific paper. European Journal of Anaesthesiology, 43(3), 262-267.

Sollaci, L. B., Enneking, W., \& Pereira, M. (2004). The introduction, methods, results, and discussion (IMRAD) structure: A fifty-year survey. Journal of the medical library association, 92(3), 364-367.

Thrower, P. (2012, April 9). Eight reasons I rejected your article [Web log post]. Retrieved from https://www.elsevier.com/connect/8-reasons-i-rejected-your-article

World Psychiatry. (2018, April 9). About the journal [Web log post]. Retrieved from https://onlinelibrary.wiley.com/journal/20515545 